\title{
A Novel Concept in the Progression of Acute Coronary Syndrome: Acute Coronary Continuum (ACC)
}

Yu-Jun Sun and Ben $\mathrm{He}^{*}$

Heart Center, Shanghai Chest Hospital, Shanghai Jiao Tong University, Shanghai, P.R. China

*Corresponding author: Ben He, Director of the Heart Center, Shanghai Chest Hospital, Shanghai Jiao Tong University, 241 West Huaihai Road, Shanghai, 200030, P.R. China, Tel: + 86 13916443231; E-mail: drheben@126.com

Received: January 19, 2019; Accepted: February 07, 2019; Published: February 11, 2019

Copyright: (c) 2019 Yu-Jun Sun, et al. This is an open-access article distributed under the terms of the creative commons attribution license, which permits unrestricted use, distribution, and reproduction in any medium, provided the original author and source are credited.

\begin{abstract}
This review put forward a novel concept of acute coronary continuum (ACC), which described a continuous chain throughout the up and down stream of ACS. The cardiovascular continuum developed and formalized in late 1980s by Dzau and Braunwald contributed to various interventions targeting this chain at multiple sites and great improvements in both the primary and secondary prevention of coronary artery disease (CAD). As the central stage of the chain, acute coronary syndrome (ACS) is responsible for the large population of end-stage heart diseases and cardiovascular death. Through years of research, the authors come up with a similar specific pathophysiological process, including rupture of vulnerable plaque, acute myocardial infarction, microcirculation dysfunction and myocardial injury, which concludes to the novel concept of ACC. ACC is a novel concept which establish a comprehensive understanding of ACS. It links the initial pathophysiological process to clinical manifestations of ACS and its residual risks. The review summarizes what is newly known and what remains unknown about each event involved in this novel continuum. It describes the most common sequential clinical problems in ACS: what causes plaque rupture and how to identify plaque destabilization, what is the optimal reperfusion strategy for AMI, how to deal with microcirculation dysfunction, and how to identify myocardial injury and improve post-MI heart protection. The formalization of ACC will help enhance understanding of ACS and provide guidelines for future research.
\end{abstract}

Keywords: Acute coronary syndrome; Acute coronary continuum; Plaque rupture

\section{Introduction}

Ischemic heart disease has developed to be the top single health killer in the last 15 years, which caused over 8 million deaths in 2015 [1]. The concept of a progressive pathophysiological chain underling the disease - the cardiovascular continuum - was developed and formalized in late 1980s by Dzau and Braunwald [2]. In the past several decades, various interventions targeting this chain at multiple sites have emerged and contributed to great improvements in both the primary and secondary prevention of coronary artery disease (CAD). As the central stage of the chain, acute coronary syndrome (ACS) often occurs as a life-threatening event and leads to impaired heart function, responsible for the large population of end-stage heart diseases and cardiovascular death. Similarly, several crucial events play important roles in the progression of ACS, including rupture of vulnerable plaque, acute myocardial infarction, microcirculation dysfunction and myocardial injury. These specific pathophysiological processes constitute a continuous chain throughout the up and down stream of ACS, which comes to the novel concept of acute coronary continuum (ACC). ACC establish a comprehensive understanding of ACS. It links the initial pathophysiological process to clinical manifestations of disease and its residual risks. The chain holds the key to the prevention, treatment and rehabilitation of ACS and provides pathophysiological targets for innovative researches. Figure 1 depicted the sequential chain of ACC.

Despite the notable efforts that have been made in exploring the mechanism underlying the acute disease, challenges still exist at each level in the chain leading to irreversible heart dysfunction. The purpose of this review is to summarize what is newly known and what remains unknown about each event involved in this novel continuum. Although not all researches can be addressed or discussed in depth, the information presented here help better understand the novel concept of ACC and might help provide guidelines for future research.

\section{Literature Review}

\section{Part I: Rupture of vulnerable plaque: The initiation of ACC}

The concept of plaque rupture, known as the initial process of acute coronary events, was first reported in $1844[3,4]$. The connection between plaque stability with coronary thrombus had not been well demonstrated until the mid-20th century [5]. The vulnerable plaque is defined as a lesion consisting of a necrotic core with an overlying thin ruptured fibrous cap whose disruption exposes the highly thrombogenic material of the core to the blood. Plaque rupture reportedly contributes to $75 \%$ of the thrombi responsible for ACS and is widely accepted as the leading cause of coronary thrombus [6-8]. Thus, the mechanism underlying the conversion of the plaque from stable to vulnerable phenotypes is of great importance in understanding how the atherosclerotic lesions develop.

The absence of proper animal models has hampered the efficiency of basic research on plaque destabilization. An optimal animal model must bear close resemblance to the pathophysiological processes of human beings. Tremendous efforts have been devoted to generating an efficient model for vulnerable plaque with high rate of plaque rupture and luminal thrombus. In recent years, breakthrough occurred with the emergence of apolipoprotein E (ApoE) knockout mice $[9,10]$. With a high cholesterol diet, these mice experience development of 
atheromata and mimic similar features to those of human advanced plaques, but plaque rupture and luminal thrombosis are rarely observed in murine atherosclerosis [11]. Hence, various approaches were studied to generate plaque destabilization. Surgical alteration of perivascular blood flow is the most common method [12-19]. Variants were established based on different combined use of common carotid artery ligation, local shear modification, tandem stenosis and surgical induced endogenous activation of Renin-angiotensin-aldosterone System (RAAS) [16-19]. Furthermore, models were extended by additional genetic manipulation. Overexpression of the proapoptotic protein p53, matrix metalloproteinase-9 (MMP-9), imposed hypercoagulability and human diphtheria toxin administration were reported to increase apoptotic cell accumulation, plaque inflammation and events of plaque disruption, intraplaque hemorrhage, or luminal thrombosis [5,13-15]. Despite the limited possibility of genetic modification that hampers the use of rabbit and porcine models in the understanding of plaque destabilization pathophysiology, these large animal models are suitable for the assessment of novel imaging techniques, stabilizing therapies, and cardiovascular surgical techniques [20-22].

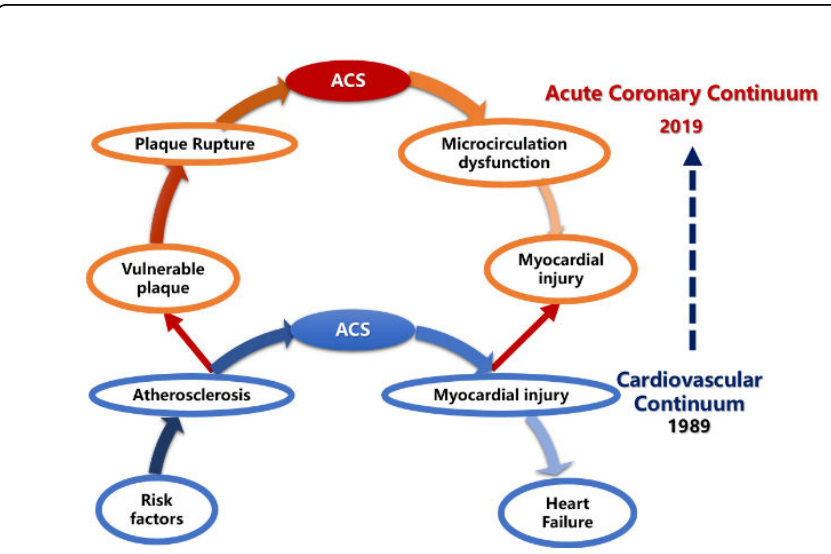

Figure 1: Acute coronary continuum.

Thanks to efficient animal models, mechanisms leading to plaque destabilization can be studied in vivo. Series of studies have demonstrated the cellular change during the lesion development. Smooth muscle cell (SMC) apoptosis triggers plaque vulnerability with reduced matrix protein deposition, aggravated plaque inflammation and expanded necrotic core (NC) [5]. As an alternative mechanism of SMC apoptosis, loss of cell matrix and cell-to-cell interactions are found after matrix metalloproteinase (MMP)-dependent degradation $[23,24]$. Meanwhile, autophagy death was also identified as a way of macrophage removal to prevent apoptosis and promote the clearance of reactive oxygen species production $[25,26]$. However, macrophages revealed opposite stage-dependent effects during the progression of atherosclerosis [25,27]. The continuous exposure to stressors inhibits autophagy in favor of an apoptosis-mediated macrophage death, contributing to enlarged NC size and plaque inflammation [25-27]. Data showed that unbalanced activity of endoplasmic reticulum (ER) stress pathways and nuclear receptors may be crucial in promoting macrophage apoptosis [25-36]. Deficiency of the homologous protein (CHOP), which mediates mitochondria- dependent apoptosis through the downregulation of $\mathrm{Bcl}-2$ and triggers ER calcium release, critically reduces atheroma burden and lesional apoptosis [28-30]. GFP-Nur77 has been reported to inhibit differentiation of oxLDL-treated macrophages into DC [31-36]. Despite the increasing knowledge about mechanisms underlying macrophage apoptosis, the key molecules underlying its induction and phenotype differentiation remain elusive. During atherosclerosis, defective cell efferocytosis results in the accumulation of apoptotic cells and the delay of resolution of inflammation [37]. Apoptotic cells produce a plethora of find-me and eat-me signals that mediate phagocyte attraction, interaction, and, finally, engulfment [38]. Both efferocytosis- related receptor competition and impaired function of lesional macrophages during phagocytosis may hamper efferocytosis [39-43]. Protease-driven degradation of extracellular matrix (ECM) is a dominant process leading to mechanical weakening of the fibrous cap, which precedes plaque rupture and consequent secondary thrombotic events $[44,45]$. MMP family members, such as MMP-8, MMP-9, or MMP-12, correlate with plaque instability and risk for ACS [46,47]. However, results from studies using MMP transgenic or knockout mice indicated divergent effect of MMP family members. For instance, MMP-8MMP-9 and MMP-12 are related with the induction of a vulnerable plaque phenotype [45,48-50], while MMP-2 and MMP-3 represented beneficial function $[45,51,52]$.

Clinically, early detection of vulnerable plaque in asymptomatic patients is of great importance to the prevention and treatment of ACS. The development of intravascular imaging provides new methods to identify high-risk plaques. The PROSPECT study demonstrated that most of the non-culprit lesions characterized by large plaque burden $(>70 \%)$, small luminal area $(<4 \mathrm{~mm} 2)$, and presence of thin-cap fibroatheroma in virtual histology intravascular ultrasound $\mathrm{VH}-$ IVUS) were associated with clinical events [53]. However, the predictive value of these features was low [53]. Near-infrared spectroscopy (NIRS) is able to discriminate lipid-rich atherosclerotic plaque with high sensitivity and specificity in vitro [54]. Hence, the combined use of NIRS and VH-IVUS provides the possibility of detecting lipid-rich atheroma in vivo $[55,56]$. Three intravascular ultrasound (IVUS) have been associated with coronary artery disease instability: echo attenuation, an intraplaque echolucent zone, and spotty calcification [57-61]. A recent study comparing IVUS with nearinfrared spectroscopic detection of lipid core plaque and histopathology in vessel segments at necropsy demonstrated that echoattenuated plaque, especially superficial echo attenuation, was the most reliable IVUS signature for identifying a high-risk plaque [62]. Molecular imaging enables the detection of key biological processes of plaque destabilization by MRI, X-ray CT, PET-CT80 or PET/MRI [63-66]. Successful imaging of destabilizing processes such as macrophage-rich plaques, neointimal cell death, protease activity or oxidative stress, have emerged as a promising complementary tool to identify subclinical lesions and have been evaluated in preclinical [67-73]. Encouraging results in these imaging researches require further clinical evaluation, especially prospective studies are needed.

\section{Part II: Acute myocardial infarction: Core clinical consequences}

The rupture of vulnerable plaque leads to acute myocardial infarction (AMI). As a common cardiac emergency and the core clinical process of ACC, AMI with or without ST-segment elevation (STEMI or non-STEMI) is associated with the potential for substantial morbidity and mortality. Ischemic heart disease has become the top single killer responsible for over 8 million deaths worldwide in 2015 [1]. Concurrently, the global burden of AMI has shifted from developed countries to low- and middle-income ones [74,75]. In the 
past three to four decades, dramatic improvements have been made in the management of AMI.

STEMI is typically characterized by a totally occluding thrombus [76]. Thanks to the rapid development and evolution in devices and techniques, the acute mortality of STEMI has progressively declined from more than $20 \%$ to less than $5 \%$ [77,78]. Despite the improvement in survival during the acute phase, there is still a trend of increasing death rate among the whole population [1]. Huge efforts are made to further optimize current treatments. Traditionally, there are two main methods for emergency revascularization, thrombolysis and percutaneous coronary intervention (PCI). Both have their unique advantages. Thrombolysis can achieve fast reperfusion with a simple injection of fibrinolytic agents. However, only $50-60 \%$ patients could achieve complete reperfusion with thrombolysis alone, which increases the risk of recurrent ischemia $[79,80]$. PCI used to be considered prior to thrombolysis with the advantages of lower rates of early death, reinfarction, and intracranial hemorrhage. Undoubtedly, PCI prompt with door-to-balloon time $\leq 90$ minutes as guidelines recommended is the preferred approach for STEMI with onset of symptoms within the previous 12 hours [76]. The development of chest pain center contributed to rapid diagnosis and treatment of AMI. Nevertheless, still a proportion of patients with STEMI cannot receive timely primary PCI due to lack of facilities or delays in patient transfer or catheterization team mobilization. The advantages of easy administration, widespread availability and early patency of the infarct-related artery (IRA) make thrombolysis an ideal alternative on the occasion where in-time PCI is unavailable. Hence, the concept of pharmaco-invasive emerges. Early routine post-thrombolysis has been proved to be a reasonable, useful strategy to bridge the time gap to complete revascularization [80-86]. In these patients, despite a propensity for more bleeding, pharmaco-invasive strategy was associated with similar clinical efficacy as compared with primary PCI, even in patients presenting within 3 hours after symptom onset and unable to undergo primary PCI within 1 hour [82,84]. Shorter symptom-to-reperfusion time, higher culprit-vessel patency, and similar clinical outcome were observed in STEMI patients receiving fibrinolysis followed by PCI [85]. Moreover, when PCI related delay is prolonged, the benefits of pharmaco-invasive strategy increase [83]. Now, thrombolysis followed by routine PCI within 2 to 24 hours is gradually accepted as a reasonable alternative reperfusion option when primary PCI is not readily available, especially in patients presenting early after symptom onset $[76,87]$. The pharmaco-invasive does not increase intramyocardial hemorrhage (IMH) and microvascular obstruction (MVO) according to cardiac magnetic resonance (CMR) [87]. The myocardial injury caused by the infarction decided the patient's outcomes. In daily practice, several indicators are used to evaluate myocardial injury, including functional (i.e., left ventricular ejection fraction, LVEF), symptomatic (i.e., NYHA classification) and clinical (i.e., age, sex, morbidities, etc.) characteristics. However, these factors may be arbitrary and changeable, or experiences dependent, so that the evaluation on the same patient may come to different conclusions with discrete method. Moreover, some of the indicators even lose their values in patients with little functional or structural changes, especially those who received timely reperfusion therapies. Undoubtedly, the stratification of myocardial injury after ACS is crucial for doctor's medical decision and patient's secondary prevention. The modern advancements of cardiac imaging technologies allow more precise determination of pathophysiologic changes during ACS. For example, CMR can visualize the tissue injury that is undetectable by traditional echocardiography and is able to identify different pathophysiological stages of ACS, including myocardial edema caused by ischemia, permanent myocardial necrosis resulting from prolonged blood blockage, microvascular obstruction (MVO)/intramyocardial hemorrhage (IMH) induced by microcirculation dysfunction, initial contracting dysfunction mostly due to myocardial stunning, compensatory cardiac remodeling triggered by extensive infarction, and the final cardiac decompensation $[88,89]$. Recently, a classification based on pathophysiological stages has been established with the combined use of CMR and echocardiography to make up the insufficient evaluations for lessinjured patients and represent a more subtle and comprehensive stratification of cardiac detriments [90]. In this novel grading system, patients are classified as Grade 0: no detectable myocardial necrosis; Grade 1: myocardial necrosis without functional and morphological abnormalities; Grade 2: myocardial necrosis with reduced LVEF; Grade 3: reduced LVEF on the basis of cardiac remodeling; Grade 4: mitral regurgitation additional to the Grade- 3 criteria [90]. The classification was documented as a good reflection of infarction size and a comparable predictor for outcomes [90], which would help improve information-interchange among doctors, self-awareness of the disease for patients and objective evaluation for post-STEMI labor capacity. Figure 2 introduced the novel evaluation system.

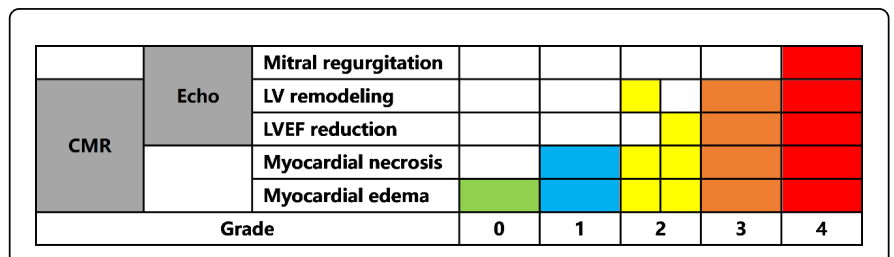

Figure 2: The novel post-MI grading system.

Partial coronary occlusion, or occlusion in the presence of collateral circulation, usually results in non-STEMI or unstable angina [91]. Patients presenting with NSTEMI is triaged to either an invasive strategy or an ischemia-guided strategy [91]. An invasive strategy is favored for the majority because of improved outcomes, and it has become consensus that the patients at higher risk benefits more from earlier revascularization [92]. With the development of antiplatelet agents, there is a trend for early intervention in NSTEMI patients. However, controversy remains on the definition of the time point. Too early may lead to complications without enough time for effective antiplatelet action, while too late can meet with ischemic risks during waiting. Series of clinical studies worked on this project, but the results were inconsistent. The underlying reason is that the definition of early or delayed timing varies [93-97]. Moreover, from 2007 to 2015, guidelines switched the time point from less than 72 hours to 24 hours [91,98-100]. Two recent meta-analysis based on the classic dual antiplatelet treatment revealed an early hazard phenomenon in intervention within 3 hours for NSTEMI, which should be taken seriously during decision $[101,102]$.

With the increasing demand for early diagnosis and treatment of ACS, a new concept of chest pain center (CPC) has generally developed to be a safe, cost-effective, and rapid approach to the evaluation, triage, and management of patients presenting with susceptible symptoms of AMI or unstable angina [103]. The popularity of CPC has contributed to cost reduction by less hospitalizations, shorter lengths of stay and fewer unnecessary treatments and procedures $[103,104]$. Its initial target to decrease waiting time to 
treatment for AMI fostered the protocol-driven mode in CPC. With the standard protocol, high- and low-risk patients can be identified on presentation and receive optimal therapeutic strategies. Nevertheless, challenges still sustain in various stages. Since that unlimited expansion of CPC is impossible, how to bridge the gap between areas with different qualities of public health system requires attention. First medical contact seems to be more and more important in the treatment of ACS. Pre-hospital thrombolysis is likely to be a safe and effective method to be added to current protocol for patients unfortunately faced with inevitable delay to primary PCI. Moreover, risk stratification of NSTEMI is of great importance for its decisive role in patients' treatment. What is the best assessment system to identify high risk patients? What is the optimal invasive time for NSTEMI at different risk levels? More works need to do to further enhance patient care in ACS.

\section{Part III: Microcirculation dysfunction prevention: Key bridge from vessel to muscle}

PCI has been well documented as the most effective method for epicardial revascularization for AMI [105-111]. However, successful epicardial reperfusion does not necessarily equate to effective myocardial perfusion, even in patients with TIMI 3 flow after successful PCI. In fact, still $20 \%$ - $40 \%$ patients with ACS remain impaired microvascular blood flow regardless of patent epicardial reperfusion [56,62]. The presence of abnormal microcirculation is associated with poor healing of the infarct and adverse left ventricular remodeling, which can result in detrimental impacts on survival [112-116]. Hence, the ultimate therapeutic goal is the complete restoration of myocardial perfusion [116-119], which calls for proper assessment methods and effective therapies.

Currently, there are two widely used myocardial perfusion angiographic parameters: TIMI myocardial perfusion grading (TMPG) [116] and myocardial blush grading (MBG) [119]. TMPG is an index that focuses on the velocity of contrast opacity clearance [116]. When damage occurs to the microcirculation, it will be evidenced by slowing of the contrast clearance and abnormal or absent myocardial blush. MBG is based on the intensity of contrast opacity of the infarcted area. These two angiographic methods are reported to have high predictive value in AMI [112,114-116,119]. However, both methods are categorical, subjective, and operator dependent [112-116]. Recently, a novel quantitative index of myocardial perfusion by angiographic frame counting, named TIMI Myocardial Perfusion Frame Count (TMPFC), that encompasses the filling and clearance time of contrast in the myocardium to evaluate the degree of myocardial perfusion has been established [120]. TMPFC allows quantification of TMPG and correlates well with these established parameters [120]. The new assessment method also represents ideal predictive value in patients undergoing primary angioplasty [120]. With the development of cardiac imaging techniques, non-invasive imaging such as gadolinium contrast magnetic resonance imaging (MRI), myocardial contrast echocardiography and nuclear imaging, have developed to effectively evaluate myocardial perfusion [121-123].

Lack of effective therapeutic methods has hampered the treatment of patients with suboptimal myocardial perfusion for decades. Vasodilator drugs was first attempted to deal with no-reflow by coronary injection during PCI. Various vasodilator agents have been tested for the coronary pharmacological therapy. Adenosine at a dose of 100 to $200 \mathrm{mg}$, nicardipine at a median dose of $400 \mathrm{mg}$, or nitroprusside at doses ranging from 50 to $300 \mathrm{mg}$, are the current standard of care [124-126]. No significant difference was observed between various pharmacological intervention strategies but resolved flow in myocardial tissue brought about significant clinical benefit [127]. Recently, intracoronary administration of glycoprotein (GP) b/a inhibitor has been reported to improve both angiographic and clinical outcomes of patients with ACS [128]. Since the traditional injection through the guiding catheter may have significant systemic effects and is considered less effective with only a small amount of agent reaching the microvascular bed, the authors recommended the use of micro infusion catheter to achieve distal coronary administration of agents. Local delivery is more likely to get better results. Predictably, along with the development of assessment system and devices, more and more effective medicines or techniques will be introduced to the treatment of microcirculation disorders.

\section{Part IV: Ischemia/Reperfusion injury and heart protection: Final goal for salvage}

Unfortunately, even if patients have received successful PCI with optimal epicardial and myocardial results, the induced reperfusion may not only contribute to the recovery of ischemic cardiac tissue but also lead to the paradoxical phenomenon of myocardial "ischemia/ reperfusion injury" (IRI) [129]. IRI brings about excessive production of reactive oxygen species (ROS)/reactive nitrogen species, the activation of apoptotic pathways, and the induction of autophagy dysfunction, all of which contribute to post-ischemic cardiomyocyte death and injury expansion [129-131]. The severity of cardiac detriments is strongly associated with patient's outcomes [132-135]. The myocardial protection has become the final stage of ACS treatment. Numerous efforts have been made to figure out the underlying mechanisms and search for novel pharmacological or molecular therapeutic targets.

During IRI, large amounts of intracellular components as alarming compounds are released and trigger inflammation [136]. In particular, nuclear proteins, such as histones, heat-shock proteins, or amphoterin, as well as nuclear DNA [137], mitochondrial DNA [138-140], ribosomal RNA [141,142] and miRNAs, play a crucial role in this process [143-145]. For instance, extracellular RNA (eRNA), together with Tumor Necrosis Factor a (TNF-a), serve as damaging factors in experimental IRI [145]. Administration of RNase1 is documented to significantly reduce the infarct area and prevent cardiomyocyte death [145].

\section{Discussion}

Cardiomyocyte apoptosis plays an important role in the pathogenesis of heart dysfunctions related to IRI [129]. Increased apoptosis results in contractile tissue loss, compensatory hypertrophy, and reparative fibrosis, all aggravate the injury [129]. Several members of the nuclear receptors have been reported to regulate cardiac apoptosis, including the peroxisome proliferator-activated receptors (PPAR- $\alpha, \beta, \gamma)$, androgen receptor, retinoic-X-receptor (RXR), and farnesoid-X-receptor (FXR) [146-149]. Besides apoptosis, ROS and autophagy dysfunction also contributed to IRI. A recent study demonstrated that VDR served as an endogenous self-defensive and cardioprotective receptor against IRI, via reducing oxidative stress, as well as inhibiting apoptosis and autophagy dysfunction-mediated cell death [150]. Interestingly, different subtypes of Liver-X-receptor (LXR) have reportedly different function [151]. Knockout of LXRa, but not LXR $\beta$, exacerbated IRI-induced oxidative/nitrative stress, and aggravated endoplasmic reticulum stress and mitochondrial 
Page 5 of 9

dysfunction [151]. The similar phenomenon was investigated in the overexpression study [151]. LXRa, but not LXR $\beta$, protects myocardium against IRI [151]. These results indicate that the nuclear receptor superfamily may represent a potential molecular therapeutic target for the treatment of cardiac disease. Regeneration is a promising strategy to treat end-edge heart diseases, especially ischemic heart failure. However, damage to myocardium is irreversible as the mammalian heart loses its ability to regenerate after birth. Hence, mechanism underlying cardiomyocyte reactivation may have great potential to protect or improve heart function. For instance, Hippo signaling has been implicated in epicardial cell proliferation, epithelial-tomesenchymal transition, and cell fate specification during cardiac organogenesis $[152,153]$. In the last decade, stem cell therapy has been introduced as a novel treatment for a (AMI) [154,155]. Intracoronary bone-marrow-derived stem cells (BMC) treatment was documented to improve both overall systolic function and mid-term diastolic function as well as exercise capacity after AMI $[156,157]$. Meanwhile, humaninduced pluripotent stem cell (iPSC)-derived cardiomyocytes were used as a tool to study cardiac arrhythmias and to evaluate the cardiac toxicity of typical drugs in vitro [158]. These researches indicated the powerful iPSC technology as value creation for understanding the mechanisms of heart diseases and a potential therapeutic opportunity for cardiac regeneration. Despite the notable strides that have been made in recent years in understanding the pathogenesis of cardiac regeneration, this field is still at an early stage.

\section{Conclusion}

In the late 1980s, Dr. Braunwald put forward the famous concept of the cardiovascular continuum, which contributed to huge progress in the research and treatment of CAD in the following decades. Along with fast economic and social development, CAD has already become the heaviest health burden worldwide. As the most severe acute manifestation of CAD, ACS is responsible for a large proportion of end-stage heart disease and cardiac death. Similar to the cardiovascular continuum, the novel concept of ACC provides a comprehensive layout of series crucial processes during the development of ACS. Underlying this novel chain is a pathophysiological continuum. It describes the most common sequential clinical problems in ACS: what causes plaque rupture and how to identify plaque destabilization, what is the optimal reperfusion strategy for AMI, how to deal with microcirculation dysfunction, and how to identify myocardial injury and improve post-MI heart protection. The formalization of ACC will help enhance understanding of ACS and clearly indicate existing challenges at each level in the chain. Further efforts in interrupting these critical stages, perhaps at multiple sites, will probably contribute to therapeutic revolution and better patient care in the coming future.

\section{Conflicts of Interest}

There are no conflicts of interest for the present study.

\section{Funding Sources}

This work was supported by the National Natural Science Foundation of China [grant number Key Program 81830010], the National Key Research and Development Program of China [grant number 2016YFC1301203], Shanghai Shen Kang Hospital Development Center [grant number 16CR1012A], Shanghai Municipal Commission of Health and Family Planning [grant number Major
Program 2014ZYJB0501], Shanghai Jiao Tong University [grant number YG2015ZD04], and the Clinical Research Center, Shanghai Jiao Tong University School of Medicine [grant number dly201512].

\section{References}

1. WHO Fact sheet http://www.who.int/mediacentre/factsheets/fs310/en/ index.html.

2. Dzau V, Braunwald E (1991) Resolved and unresolved issues in the prevention and treatment of coronary artery disease: A workshop consensus statement. Am Heart J 121: 1244-63.

3. Falk E (1992) Why do plaques rupture?. Circulation 86: III 30-42.

4. Herrick JB (1983) Clinical features of sudden obstruction of the coronary arteries. JAMA 250: 1757-1762.

5. Clarke MC, Figg N, Maguire JJ, Davenport AP, Goddard M, et al. (2006) Apoptosis of vascular smooth muscle cells induces features of plaque vulnerability in atherosclerosis. Nat Med 12: 1075-1080.

6. Ambrose JA, Tannenbaum MA, Alexopoulos D, Hjemdahl-Monsen CE, Leavy J, et al. (1988) Angiographic progression of coronary artery disease and the development of myocardial infarction. J Am Coll Cardiol 12: 56-62.

7. Muller JE, Tofler GH, Stone PH (1989) Circadian variation and triggers of onset of acute cardiovascular disease. Circulation 79: 733-743.

8. Virmani R, Kolodgie FD, Burke AP, Farb A, Schwartz SM (2000) Lessons from sudden coronary death: A comprehensive morphological classification scheme for atherosclerotic lesions. Arterioscler Thromb Vasc Biol 20: 1262-1275.

9. Plump AS, Smith JD, Hayek T, Aalto-Setälä K, Walsh A, et al. (1992) Severe hypercholesterolemia and atherosclerosis in apolipoprotein Edeficient mice created by homologous recombination in ES cells. Cell 71: 343-353.

10. Zhang SH, Reddick RL, Piedrahita JA, Maeda N (1992) Spontaneous hypercholesterolemia and arterial lesions in mice lacking apolipoprotein E. Science 258: 468-471.

11. Schwartz SM, Galis ZS, Rosenfeld ME, Falk E (2007) Plaque rupture in humans and mice. Arterioscler Thromb Vasc Biol 27: 705-713.

12. Von der ThüSen JH, Van Berkel TJ, Biessen EA (2001) Induction of rapid atherogenesis by perivascular carotid collar placement in apolipoprotein E-deficient and low-density lipoprotein receptor-deficient mice. Circulation 103: 1164-1170.

13. Von der Thusen JH, Van Vlijmen BJ, Hoeben RC, Hoeben RC, Kockx $\mathrm{MM}$, et al. (2002) Induction of atherosclerotic plaque rupture in apolipoprotein E-/- mice after adenovirus-mediated transfer of p53. Circulation 105: 2064-2070.

14. De Nooijer R, Verkleij CJ, Von der Thusen JH, Jukema JW, Van der Wall EE, et al. (2006) Lesional overexpression of matrix metalloproteinase-9 promotes intraplaque hemorrhage in advanced lesions but not at earlier stages of atherogenesis. Arterioscler Thromb Vasc Biol 26: 340-346.

15. Borissoff JI, Otten JJ, Heeneman S, Leenders P, Van Oerle R, et al. (2013) Genetic and pharmacological modifications of thrombin formation in apolipoprotein e-deficient mice determine atherosclerosis severity and atherothrombosis onset in a neutrophil-dependent manner. PloS One 8: e55784.

16. Sasaki T, Kuzuya M, Nakamura K, Cheng XW, Shibata T, et al. (2006) A simple method of plaque rupture induction in apolipoprotein E-deficient mice. Arterioscler Thromb Vasc Biol 26: 1304-1309.

17. Cheng C, Tempel D, Van Haperen R, Van der Baan A, Grosveld F, et al. (2006) Atherosclerotic lesion size and vulnerability are determined by patterns of fluid shear stress. Circulation 113: 2744-2753.

18. Jin SX, Shen LH, Nie P, Yuan W, Hu LH, et al. (2012) Endogenous renovascular hypertension combined with low shear stress induces plaque rupture in apolipoprotein E-deficient mice. Arterioscler Thromb Vasc Biol 32: 2372-2379.

19. Peter K, Chen YC, Bui AV, Diesch J, Manasseh R, et al. (2013) A novel mouse model of atherosclerotic plaque instability for drug testing and 
mechanistic/therapeutic discoveries using gene and microRNA expression profiling. Circ Res 113: 252-265.

20. Getz GS, Reardon CA (2012) Animal models of atherosclerosis. Arterioscler Thromb Vasc Biol 32: 1104-1115.

21. Johnstone MT, Perez AS, Nasser I, Stewart R, Vaidya A, et al. (2004) Angiotensin receptor blockade with candesartan attenuates atherosclerosis, plaque disruption, and macrophage accumulation within the plaque in a rabbit model. Circulation 110: 2060-2065.

22. Thim T, Hagensen MK, Drouet L, Bal CD, Bonneau M, et al. (2010) Familial hypercholesterolaemic downsized pig with human-like coronary atherosclerosis: A model for preclinical studies. EuroIntervention 6: 261-268.

23. Von Wnuck Lipinski K, Keul P, Ferri N, Lucke S, Heusch G, et al. (2006) Integrin-mediated transcriptional activation of inhibitor of apoptosis proteins protects smooth muscle cells against apoptosis induced by degraded collagen. Circ Res 98: 1490-1497.

24. Williams H, Johnson JL, Jackson CL, White SJ, George SJ (2010) MMP-7 mediates cleavage of $\mathrm{N}$-cadherin and promotes smooth muscle cell apoptosis. Cardiovasc Res 87: 137-146.

25. Gautier EL, Huby T, Witztum JL, Ouzilleau B, Miller ER, et al. (2009) Macrophage apoptosis exerts divergent effects on atherogenesis as a function of lesion stage. Circulation 119: 1795-1804.

26. Liao X, Sluimer JC, Wang Y, Subramanian M, Brown K, et al. (2012) Macrophage autophagy plays a protective role in advanced atherosclerosis. Cell Metab 15: 545-53.

27. Tabas I (2005) Consequences and therapeutic implications of macrophage apoptosis in atherosclerosis: The importance of lesion stage and phagocytic efficiency. Arterioscler Thromb Vasc Biol 25: 2255-2264.

28. Thorp E, Li G, Seimon TA, Kuriakose G, Ron D, et al. (2009) Reduced apoptosis and plaque necrosis in advanced atherosclerotic lesions of Apoe -I- and Ldlr-/- mice lacking CHOP. Cell Metab 9:474-481.

29. Myoishi M, Hao H, Minamino T, Watanabe K, Nishihira K, et al. (2007) Increased endoplasmic reticulum stress in atherosclerotic plaques associated with acute coronary syndrome. Circulation 116: 1226-1233.

30. Thorp E, Li Y, Bao L, Yao PM, Kuriakose G, et al. (2009) Brief report: Increased apoptosis in advanced atherosclerotic lesions of Apoe-/- mice lacking macrophage Bcl-2. Arterioscler Thromb Vasc Biol 29: 169-172.

31. Lim WS, Timmins JM, Seimon TA, Sadler A, Kolodgie FD, et al. (2008) Signal transducer and activator of transcription-1 is critical for apoptosis in macrophages subjected to endoplasmic reticulum stress in vitro and in advanced atherosclerotic lesions in vivo. Circulation 117: 940-951.

32. Seimon TA, Nadolski MJ, Liao X, Magallon J, Nguyen M, et al. (2010) Atherogenic lipids and lipoproteins trigger CD36-TLR2-dependent apoptosis in macrophages undergoing endoplasmic reticulum stress. Cell Metab 12: 467-482.

33. Seimon TA, Obstfeld A, Moore KJ, Golenbock DT, Tabas I (2006) Combinatorial pattern recognition receptor signaling alters the balance of life and death in macrophages. Proc Natl Acad Sci USA 103: 19794-19799.

34. Seimon TA, Wang Y, Han S, Senokuchi T, Schrijvers DM, et al. (2009) Macrophage deficiency of $\mathrm{p} 38 \mathrm{a}$ MAPK promotes apoptosis and plaque necrosis in advanced atherosclerotic lesions in mice. J Clin Invest 119: 886-898.

35. Wei Y, Wang D, Topczewski F, Pagliassotti MJ (2006) Saturated fatty acids induce endoplasmic reticulum stress and apoptosis independently of ceramide in liver cells. Am J Physiol Endocrinol Metab 291: E-275-281.

36. Hu LH, Yu Y, Jin SX, Nie P, Cai ZH, et al. (2014) Orphan nuclear receptor Nur-77 Inhibits Oxidized LDL-induced differentiation of RAW264. 7 murine macrophage cell line into dendritic like cells. BMC Immunol 15 54 .

37. Schrijvers DM, De Meyer GR, Kockx MM, Herman AG, Martinet W (2005) Phagocytosis of apoptotic cells by macrophages is impaired in atherosclerosis. Arterioscler Thromb Vasc Biol 25: 1256-1261.

38. Ravichandran KS (2011) Beginnings of a good apoptotic meal: The findme and eat-me signaling pathways. Immunity 35: 445-455.
39. Li S, Sun Y, Liang CP, Thorp EB, Han S, et al. (2009) Defective phagocytosis of apoptotic cells by macrophages in atherosclerotic lesions of ob/ob mice and reversal by a fish oil diet. Circ Res 105: 1072-1082.

40. Thorp E, Cui D, Schrijvers DM, Kuriakose G, Tabas I (2008) Mertk receptor mutation reduces efferocytosis efficiency and promotes apoptotic cell accumulation and plaque necrosis in atherosclerotic lesions of Apoe -/- mice. Arterioscler Thromb Vasc Biol 28: 1421-1428.

41. Thorp E, Vaisar T, Subramanian M, Mautner L, Blobel C, et al. (2011) Shedding of the MER tyrosine kinase receptor is mediated by ADAM17 through a pathway involving reactive oxygen species, protein kinase $\delta$, and p38 mitogen-activated protein kinase (MAPK). J Biol Chem: 286: 33335-33344.

42. Sather S, Kenyon KD, Lefkowitz JB, Liang X, Varnum BC, et al. (2007) A soluble form of the Mer receptor tyrosine kinase inhibits macrophage clearance of apoptotic cells and platelet aggregation. Blood 109: 1026-1033.

43. Driscoll WS, Vaisar T, Tang J, Wilson CL, Raines EW (2013) Macrophage ADAM17 deficiency augments CD36-dependent apoptotic cell uptake and the linked anti-inflammatory phenotype. Circ Res 113: 52-61.

44. Newby AC (2012) Matrix metalloproteinase inhibition therapy for vascular diseases. Vascul Pharmacol 56: 232-244.

45. Johnson JL, George SJ, Newby AC, Jackson CL (2005) Divergent effects of matrix metalloproteinases $3,7,9$, and 12 on atherosclerotic plaque stability in mouse brachiocephalic arteries. Proc Natl Acad Sci USA 102: 15575-15580.

46. Peeters W, Moll FL, Vink A, Van der Spek PJ, De Kleijn DP, et al. (2011) Collagenase matrix metalloproteinase-8 expressed in atherosclerotic carotid plaques is associated with systemic cardiovascular outcome. Eur Heart J 32: 2314-2325.

47. Scholtes VP, Johnson JL, Jenkins N, Sala-Newby GB, De Vries JP, et al. (2012) Carotid atherosclerotic plaque matrix metalloproteinase-12positive macrophage subpopulation predicts adverse outcome after endarterectomy. J Am Heart Assoc 1: e001040.

48. Gough PJ, Gomez IG, Wille PT, Raines EW (2006) Macrophage expression of active MMP-9 induces acute plaque disruption in apoEdeficient mice. J Clin Invest 116: 59-69.

49. Laxton RC, Hu Y, Duchene J, Zhang F, Zhang Z, et al. (2009) A role of matrix metalloproteinase-8 in atherosclerosis. Circ Res 105: 921-929.

50. Quillard T, Tesmenitsky Y, Croce K, Travers R, Shvartz E, et al. (2011) Selective inhibition of matrix metalloproteinase-13 increases collagen content of established mouse atherosclerosis. Arterioscler Thromb Vasc Biol 31: 2464-2472.

51. Ionita MG, Van den Borne P, Catanzariti LM, Moll FL, De Vries JP, et al. (2010) High neutrophil numbers in human carotid atherosclerotic plaques are associated with characteristics of rupture-prone lesions. Arterioscler Thromb Vasc Biol 30: 1842-1848.

52. Alexander MR, Moehle CW, Johnson JL, Yang Z, Lee JK, et al. (2012) Genetic inactivation of IL-1 signaling enhances atherosclerotic plaque instability and reduces outward vessel remodeling in advanced atherosclerosis in mice. J Clin Invest 122: 70-79.

53. Stone GW, Maehara A, Lansky AJ, De Bruyne B, Cristea E, et al. (2011) A prospective natural-history study of coronary atherosclerosis. N Engl J Med 364: 226-235

54. Gardner CM, Tan H, Hull EL, Lisauskas JB, Sum ST, et al. (2008) Detection of lipid core coronary plaques in autopsy specimens with a novel catheter-based near-infrared spectroscopy system. JACC Cardiovasc Imaging 1: 638-648.

55. Waxman S, Dixon SR, L'Allier P, Moses JW, Petersen JL, et al. (2009) In vivo validation of a catheter-based near-infrared spectroscopy system for detection of lipid core coronary plaques: Initial results of the SPECTACL study. JACC Cardiovasc Imaging 2: 858-868.

56. Pu J, Mintz GS, Brilakis ES, Banerjee S, Abdel-Karim AR, et al. (2011) In vivo characterization of coronary plaques: Novel findings from comparing greyscale and virtual histology intravascular ultrasound and near-infrared spectroscopy. Eur Heart J 33: 372-383. 
57. Wu X, Mintz GS, Xu K, Lansky AJ, Witzenbichler B, et al. (2011) The relationship between attenuated plaque identified by intravascular ultrasound and no-reflow after stenting in acute myocardial infarction: The HORIZONS-AMI (Harmonizing Outcomes With Revascularization and Stents in Acute Myocardial Infarction) trial. JACC Cardiovasc Interv 4: 495-502.

58. Lee T, Kakuta T, Yonetsu T, Takahashi K, Yamamoto G, et al. (2011) Assessment of echo-attenuated plaque by optical coherence tomography and its impact on post-procedural creatine kinase-myocardial band elevation in elective stent implantation. JACC Cardiovasc Interv 4: 483-491.

59. Yamagishi M, Terashima M, Awano K, Kijima M, Nakatani S, et al. (2000) Morphology of vulnerable coronary plaque: Insights from follow-up of patients examined by intravascular ultrasound before an acute coronary syndrome. J Am Coll Cardiol 35: 106-111.

60. Ehara S, Kobayashi Y, Yoshiyama M, Shimada K, Shimada Y, et al. (2004) Spotty calcification typifies the culprit plaque in patients with acute myocardial infarction: An intravascular ultrasound study. Circulation 110: 3424-3429.

61. Kataoka Y, Wolski K, Uno K, Puri R, Tuzcu EM, et al. (2012) Spotty calcification as a marker of accelerated progression of coronary atherosclerosis: Insights from serial intravascular ultrasound. J Am Coll Cardiol 59: 1592-1597.

62. Pu J, Mintz GS, Biro S, Lee JB, Sum ST, et al. (2014) Insights into echoattenuated plaques, echolucent plaques, and plaques with spotty calcification: Novel findings from comparisons among intravascular ultrasound, near-infrared spectroscopy, and pathological histology in 2,294 human coronary artery segments. J Am Coll Cardiol 63: 2220-2233.

63. Quillard T, Libby P (2012) Molecular imaging of atherosclerosis for improving diagnostic and therapeutic development. Circ Res 111: 231-244.

64. Nahrendorf M, Zhang H, Hembrador S, Panizzi P, Sosnovik DE, et al. (2008) Nanoparticle PET-CT imaging of macrophages in inflammatory atherosclerosis. Circulation 117: 379-387.

65. Majmudar MD, Yoo J, Keliher EJ, Truelove JJ, Iwamoto Y, et al. (2013) Polymeric nanoparticle PET/MR imaging allows macrophage detection in atherosclerotic plaques. Circ Res 112: 755-761.

66. Figueroa AL, Subramanian SS, Cury RC, Truong QA, Gardecki JA, et al. (2011) Distribution of inflammation within carotid atherosclerotic plaques with high risk morphological features: A comparison between PET activity, plaque morphology and histopathology. Circ Cardiovasc Imaging 5: 69-77.

67. Burtea C, Ballet S, Laurent S, Rousseaux O, Dencausse A, et al. (2012) Development of a magnetic resonance imaging protocol for the characterization of atherosclerotic plaque by using vascular cell adhesion molecule-1 and apoptosis-targeted ultrasmall superparamagnetic iron oxide derivatives. Arterioscler Thromb Vasc Biol 32: e36-48.

68. Hyafil F, Vucic E, Cornily JC, Sharma R, Amirbekian V, et al. (2010) Monitoring of arterial wall remodelling in atherosclerotic rabbits with a magnetic resonance imaging contrast agent binding to matrix metalloproteinases. Eur Heart J 32: 1561-1571.

69. Jaffer FA, Kim DE, Quinti L, Tung CH, Aikawa E, et al. (2007) Optical visualization of cathepsin $\mathrm{K}$ activity in atherosclerosis with a novel, protease-activatable fluorescence sensor. Circulation 115: 2292-2298.

70. Kietselaer BL, Reutelingsperger CP, Heidendal GA, Daemen MJ, Mess WH, et al. (2004) Noninvasive detection of plaque instability with use of radiolabeled annexin A5 in patients with carotid-artery atherosclerosis. $\mathrm{N}$ Engl J Med 350: 1472-1473.

71. Briley-Saebo KC, Nguyen TH, Saeboe AM, Cho YS, Ryu SK, et al. (2012) In vivo detection of oxidation-specific epitopes in atherosclerotic lesions using biocompatible manganese molecular magnetic imaging probes. Am Coll Cardiol 59: 616-626.

72. Ronald JA, Chen JW, Chen Y, Hamilton AM, Rodriguez E, et al. (2009) Enzyme-sensitive magnetic resonance imaging targeting myeloperoxidase identifies active inflammation in experimental rabbit atherosclerotic plaques. Circulation 120: 592-599.
73. Giannarelli C, Ibanez B, Cimmino G, Ruiz JM, Faita F, et al. (2010) Contrast-enhanced ultrasound imaging detects intraplaque neovascularization in an experimental model of atherosclerosis. JACC Cardiovasc Imaging 3: 1256-1264.

74. Murray CJ, Barber RM, Foreman KJ, Ozgoren A, Abd-Allah F, et al. (2015) Global, regional, and national disability-adjusted life years (DALYs) for 306 diseases and injuries and healthy life expectancy (HALE) for 188 countries, 1990-2013: Quantifying the epidemiological transition. Lancet 386: 2145-2191.

75. Murray CJ, Vos T, Lozano R, Naghavi M, Flaxman AD, et al. (2012) Disability-adjusted life years (DALYs) for 291 diseases and injuries in 21 regions, 1990-2010: A systematic analysis for the Global Burden of Disease Study 2010. Lancet 380: 2197-2223.

76. O'Gara PT, Kushner FG, Ascheim DD, Casey DE, Chung MK, et al. (2013) $2013 \mathrm{ACCF} / \mathrm{AHA}$ guideline for the management of ST-elevation myocardial infarction: A report of the American College of Cardiology Foundation/American Heart Association Task Force on Practice Guidelines. J Am Coll Cardiol 61: e78-140.

77. Palmerini T, Biondi-Zoccai G, Della Riva D, Mariani A, Sabaté M, et al. (2013) Clinical outcomes with drug-eluting and bare-metal stents in patients with ST-segment elevation myocardial infarction: evidence from a comprehensive network meta-analysis. J Am Coll Cardiol 62: 496-504.

78. Valgimigli M, Gagnor A, Calabró P, Frigoli E, Leonardi S, et al. (2015) Radial versus femoral access in patients with acute coronary syndromes undergoing invasive management: A randomised multicentre trial. Lancet 385: 2465-2476.

79. Gibson CM (1999) Primary angioplasty compared with thrombolysis: New issues in the era of glycoprotein IIb/IIIa inhibition and intracoronary stenting. Ann Intern Med Title 130: 841-847.

80. Shen LH, Wan F, Shen L, Ding S, Gong XR, et al. (2012) Pharmacoinvasive therapy for ST elevation myocardial infarction in China: A pilot study. J Thromb Thrombolysis 33: 101-108.

81. Larson DM, Duval S, Sharkey SW, Garberich RF, Madison JD, et al. (2011) Safety and efficacy of a pharmaco-invasive reperfusion strategy in rural ST-elevation myocardial infarction patients with expected delays due to long-distance transfers. Eur Heart J 33: 1232-1240.

82. Sinnaeve PR, Armstrong PW, Gershlick AH, Goldstein P, Wilcox R, et al. (2014) ST-segment-elevation myocardial infarction patients randomized to a pharmaco-invasive strategy or primary percutaneous coronary intervention: A strategic reperfusion early after myocardial infarction (STREAM) 1-year mortality follow-up. Circulation 130: 1139-1145.

83. Gershlick AH, Westerhout CM, Armstrong PW, Huber K, Halvorsen S, et al. (2015) Impact of a pharmacoinvasive strategy when delays to primary PCI are prolonged. Heart 101: 692-698.

84. Rashid MK, Guron N, Bernick J, Wells GA, Blondeau M, et al. (2016) Safety and efficacy of a pharmacoinvasive strategy in ST-segment elevation myocardial infarction: A patient population study comparing a pharmacoinvasive strategy with a primary percutaneous coronary intervention strategy within a regional system. JACC Cardiovasc Interv 9: 2014-2020.

85. Sim DS, Jeong MH, Ahn Y, Kim YJ, Chae SC (2016) Pharmacoinvasive strategy versus primary percutaneous coronary intervention in patients with st-segment-elevation myocardial infarction: A propensity scorematched analysis. Circ Cardiovasc Interv 9 .

86. Siontis KC, Barsness GW, Lennon RJ, Holmen JL, Wright RS, et al. (2016) Pharmacoinvasive and primary percutaneous coronary intervention strategies in st-elevation myocardial infarction (from the Mayo Clinic STEMI Network). Am J Cardiol 117: 1904-1910.

87. Pu J, Ding S, Ge H, Han Y, Guo J, et al. (2017) Efficacy and safety of a pharmaco-invasive strategy with half-dose alteplase versus primary angioplasty in ST-segment-elevation myocardial infarction: Early-myotrial (early routine catheterization after alteplase fibrinolysis versus primary PCI in acute St-segment-elevation myocardial infarction). Circulation 136: 1462-1473.

88. Bruder O, Breuckmann F, Jensen C, Jochims M, Naber CK, et al. (2008) Prognostic impact of contrast-enhanced CMR early after acute ST 
segment elevation myocardial infarction (STEMI) in a regional STEMI network. Herz Kardiovaskuläre Erkrankungen 33: 136-142.

89. Dweck MR, Williams MC, Moss AJ, Newby DE, Fayad ZA (2016) Computed tomography and cardiac magnetic resonance in ischemic heart disease. J Am Coll Cardiol 68: 2201-2216.

90. He B, Ge H, Yang F, Sun Y, Li Z, et al. (2015) A novel method in the stratification of post-myocardial-infarction patients based on pathophysiology. PloS One 10: e0130158.

91. Amsterdam EA, Wenger NK, Brindis RG, Casey DE, Ganiats TG, et al. (2014) 2014 AHA/ACC guideline for the management of patients with non-ST-elevation acute coronary syndromes: A report of the American College of Cardiology/American Heart Association Task Force on Practice Guidelines. J Am Coll Cardiol 64: e139-228.

92. Fox KA, Clayton TC, Damman P, Pocock SJ, De Winter RJ, et al. (2010) Long-term outcome of a routine versus selective invasive strategy in patients with non-ST-segment elevation acute coronary syndrome: A meta-analysis of individual patient data. J Am Coll Cardiol 55: 2435-2445.

93. Neumann FJ, Kastrati A, Pogatsa-Murray G, Mehilli J, Bollwein H, et al. (2003) Evaluation of prolonged antithrombotic pretreatment (cooling-off strategy) before intervention in patients with unstable coronary syndromes: A randomized controlled trial. JAMA 290: 1593-1599.

94. Montalescot G, Cayla G, Collet JP, Elhadad S, Beygui F, et al. (2009) Immediate vs. delayed intervention for acute coronary syndromes: A randomized clinical trial. JAMA 302: 947-954.

95. Mehta SR, Granger CB, Boden WE, Steg PG, Bassand JP, et al. (2009) Early versus delayed invasive intervention in acute coronary syndromes. N Engl J Med 360: 2165-2175

96. Thiele H, Rach J, Klein N, Pfeiffer D, Hartmann A, et al. (2011) Optimal timing of invasive angiography in stable non-ST-elevation myocardial infarction: The Leipzig Immediate versus early and late Percutaneous coronary Intervention triAl in NSTEMI (LIPSIA-NSTEMI Trial). Eur Heart J 33: 2035-2043.

97. Sorajja P, Gersh BJ, Cox DA, McLaughlin MG, Zimetbaum P, et al. (2010) Impact of delay to angioplasty in patients with acute coronary syndromes undergoing invasive management: Analysis from the ACUITY (Acute Catheterization and Urgent Intervention Triage strategY) trial. J Am Coll Cardiol 55: 1416-1424.

98. Anderson JL, Adams CD, Antman EM, Bridges CR, Califf RM, et al. (2007) ACC/AHA 2007 guidelines for the management of patients with unstable angina/non-ST-elevation myocardial infarction: A report of the American college of cardiology/American heart association task force on practice guidelines (writing committee to revise the 2002 guidelines for the management of patients with unstable angina/non-ST-elevation myocardial infarction) developed in collaboration with the American college of emergency physicians, the society for cardiovascular angiography and interventions, and the society of thoracic surgeons endorsed by the american association of cardiovascular and pulmonary rehabilitation and the society for academic emergency medicine. J Am Coll Cardiol 50: e1-e157.

99. Wright RS, Anderson JL, Adams CD, Bridges CR, Casey DE, et al. (2011) 2011 ACCF/AHA focused update incorporated into the ACC/AHA 2007 guidelines for the management of patients with unstable angina/non-STelevation myocardial infarction: A report of the American college of cardiology foundation/American heart association task force on practice guidelines. J Am Coll Cardiol 57: e215-367.

100. Steg PG, James SK, Atar D, Badano LP, Lundqvist CB, et al. (2012) ESC Guidelines for the management of acute myocardial infarction in patients presenting with ST-segment elevation. Eur Heart J 33: 2569-2619.

101. Jiang M, He B, Zhang Q (2012) Timing of early invasive intervention in patients with moderate to high risk acute coronary syndromes. J Interv Cardiol 25: 10-18

102. Jiang M, Mao JL, Pu J, He B (2014) Timing of early angiography in nonST elevation acute coronary syndrome. J Invasive Cardiol 26: 47-54

103. Storrow AB, Gibler WB (2000) Chest pain centers: Diagnosis of acute coronary syndromes. Ann Emerg Med 35: 449-461.
104. Amsterdam EA, Lewis WR, Kirk JD, Diercks DB, Turnipseed S (2002) Acute ischemic syndromes: Chest pain center concept. Cardiol Clin 20: $117-136$.

105. Keeley EC, Boura JA, Grines CL (2003) Primary angioplasty versus intravenous thrombolytic therapy for acute myocardial infarction: A quantitative review of 23 randomised trials. Lancet 361: 13-20.

106. Keeley EC, Boura JA, Grines CL (2006) Comparison of primary and facilitated percutaneous coronary interventions for ST-elevation myocardial infarction: Quantitative review of randomised trials. Lancet. 367: 579-588.

107. Boersma E (2006) Does time matter? A pooled analysis of randomized clinical trials comparing primary percutaneous coronary intervention and in-hospital fibrinolysis in acute myocardial infarction patients. Eur Heart J 27: 779-788.

108. Mehta RH, Granger CB, Alexander KP, Bossone E, White HD, et al. (2005) Reperfusion strategies for acute myocardial infarction in the elderly: Benefits and risks. J Am Coll Cardiol 45: 471-478.

109. Borden WB, Faxon DP (2006) Facilitated percutaneous coronary intervention. J Am Coll Cardiol 48: 1120-1128.

110. Le May MR, Wells GA, Labinaz M, Davies RF, Turek M, et al. (2005) Combined angioplasty and pharmacological intervention versus thrombolysis alone in acute myocardial infarction (CAPITAL AMI study). J Am Coll Cardiol 46: 417-424.

111. Boden WE, Eagle K, Granger CB (2007) Reperfusion strategies in acute ST-segment elevation myocardial infarction: A comprehensive review of contemporary management options. J Am Coll Cardiol 50: 917-929.

112. Tarantini G, Ramondo A, Napodano M, Bilato C, Isabella G, et al. (2004) Myocardial perfusion grade and survival after percutaneous transluminal coronary angioplasty in patients with cardiogenic shock. Am J Cardiol 93: 1081-1085.

113. De Luca G, Suryapranata H, De Boer MJ, Ottervanger JP, Hoorntje JC, et al. (2007) Combination of electrocardiographic and angiographic markers of reperfusion in the prediction of infarct size in patients with ST-segment elevation myocardial infarction undergoing successful primary angioplasty. Int J Cardiol 117: 232-237.

114. De Luca G, van't Hof AW, Ottervanger JP, Hoorntje JC, Gosselink AM, et al. (2005) Unsuccessful reperfusion in patients with ST-segment elevation myocardial infarction treated by primary angioplasty. Am Heart J 150: 557-562.

115. Araszkiewicz A, Lesiak M, Grajek S, Prech M, Grygier M, et al. (2007) Effect of microvascular reperfusion on prognosis and left ventricular function in anterior wall myocardial infarction treated with primary angioplasty. Int J Cardiol 114: 183-187.

116. Gibson CM, Cannon CP, Murphy SA, Ryan KA, Mesley R, et al. (2000) Relationship of TIMI myocardial perfusion grade to mortality after administration of thrombolytic drugs. Circulation 101: 125-130.

117. Korosoglou G, Hansen A, Hoffend J, Gavrilovic G, Wolf D, et al. (2004) Comparison of real-time myocardial contrast echocardiography for the assessment of myocardial viability with fluorodeoxyglucose-18 positron emission tomography and dobutamine stress echocardiography. Am J Cardiol 94: 570-576.

118. Korosoglou G, Labadze N, Giannitsis E, Bekeredjian R, Hansen A, et al. (2005) Usefulness of real-time myocardial perfusion imaging to evaluate tissue level reperfusion in patients with non-ST-elevation myocardial infarction. Am J Cardiol 95: 1033-1038.

119. Van 't Hof AW, Liem A, Suryapranata H, Hoorntje JC, De Boer MJ, et al. (1998) Angiographic assessment of myocardial reperfusion in patients treated with primary angioplasty for acute myocardial infarction: Myocardial blush grade. Circulation 97: 2302-2306.

120. Ding S, Pu J, Qiao ZQ, Shan P, Song W, et al. (2010) TIMI myocardial perfusion frame count: A new method to assess myocardial perfusion and its predictive value for short-term prognosis. Catheter Cardiovasc Interv 75: $722-732$

121. Belcik JT, Davidson BP, Foster T, Qi Y, Zhao Y, et al. (2015) Contrastenhanced ultrasound assessment of impaired adipose tissue and muscle perfusion in insulin-resistant mice. Circ Cardiovasc Imaging 8: e002684. 
122. Lonnebakken MT, Staal EM, Nordrehaug JE, Gerdts E (2011) Usefulness of contrast echocardiography for predicting the severity of angiographic coronary disease in non-ST-elevation myocardial infarction. Am J Cardiol 107: 1262-1267.

123. Esteves FP, Travin MI (2014) The role of nuclear cardiology in the diagnosis and risk stratification of women with ischemic heart disease InSeminars in nuclear medicine. WB Saunders 44: 423-438.

124. Grygier M, Araszkiewicz A, Lesiak M, Grajek S (2013) Role of adenosine as an adjunct therapy in the prevention and treatment of no-reflow phenomenon in acute myocardial infarction with ST segment elevation: A review of the current data. Kardiol Pol 71: 115-120.

125. Fischell TA, Maheshwari A (2004) Current applications for nicardipine in invasive and interventional cardiology. J Invasive Cardiol 16: 428-432.

126. Wang HJ, Lo PH, Lin JJ, Lee H, Hung JS (2004) Treatment of slow/noreflow phenomenon with intracoronary nitroprusside injection in primary coronary intervention for acute myocardial infarction. Catheter Cardiovasc Interv 63: 171-176.

127. Rezkalla SH, Dharmashankar KC, Abdalrahman IB, Kloner RA (2010) No-reflow phenomenon following percutaneous coronary intervention for acute myocardial infarction: Incidence, outcome, and effect of pharmacologic therapy. J Interv Cardiol 23: 429-436.

128. Thiele H, Schindler K, Friedenberger J, Eitel I, Fürnau G, et al. (2008) Intracoronary compared with intravenous bolus abciximab application in patients with ST-elevation myocardial infarction undergoing primary percutaneous coronary intervention: The randomized Leipzig immediate percutaneous coronary intervention abciximab IV versus IC in STelevation myocardial infarction trial. Circulation 118: 49-57.

129. Movassagh M, Foo RS (2008) Simplified apoptotic cascades. Heart Fail Rev 13: 111-119.

130. Gustafsson AB, Gottlieb RA (2009) Autophagy in ischemic heart disease. Circ Res 104: 150-158.

131. Morales CR, Pedrozo Z, Lavandero S, Hill JA (2014) Oxidative stress and autophagy in cardiovascular homeostasis. Antioxid Redox Signal 20: 507-518.

132. Albert NM, Lewis C (2008) Recognizing and managing asymptomatic left ventricular dysfunction after myocardial infarction. Crit Care Nurse 28: 20-37.

133. Carrabba N, Parodi G, Valenti R, Shehu M, Migliorini A, et al. (2008) Clinical implications of early mitral regurgitation in patients with reperfused acute myocardial infarction. J Card Fail 14: 48-54.

134. Sutton MG, Sharpe N (2000) Left ventricular remodeling after myocardial infarction: Pathophysiology and therapy. Circulation 101: 2981-2988.

135. Wu E, Ortiz JT, Tejedor P, Lee DC, Bucciarelli-Ducci C, et al. (2008) Infarct size by contrast enhanced cardiac magnetic resonance is a stronger predictor of outcomes than left ventricular ejection fraction or end-systolic volume index: Prospective cohort study. Heart 94: 730-736.

136. Zernecke A, Preissner KT (2016) Extracellular ribonucleic acids (RNA) enter the stage in cardiovascular disease. Circ Res 118: 469-479.

137. Vogel B, Shinagawa H, Hofmann U, Ertl G, Frantz S (2015) Acute DNase1 treatment improves left ventricular remodeling after myocardial infarction by disruption of free chromatin. Basic Res Cardiol 110: 15.

138. Yang XM, Cui L, White J, Kuck J, Ruchko MV, et al. (2015) Mitochondrially targeted Endonuclease III has a powerful anti-infarct effect in an in vivo rat model of myocardial ischemia/reperfusion. Basic Res Cardiol 110: 3.

139. Zhang YS, Liu B, Luo XJ, Li TB, Zhang JJ, et al. (2015) Nuclear cardiac myosin light chain 2 modulates $\mathrm{NADPH}$ oxidase 2 expression in myocardium: A novel function beyond muscle contraction. Basic Res Cardiol 110: 38.

140. Bliksøen M, Mariero LH, Torp MK, Baysa A, Ytrehus K, et al. (2016) Extracellular mtDNA activates NF- $\kappa B$ via toll-like receptor 9 and induces cell death in cardiomyocytes. Basic Res Cardiol 111: 42
141. Simsekyilmaz S, Cabrera-Fuentes HA, Meiler S, Kostin S, Baumer Y, et al. (2014) Role of extracellular RNA in atherosclerotic plaque formation in mice. Circulation 129: 598-606.

142. Zimmermann-Geller B, Köppert S, Fischer S, Cabrera-Fuentes HA Lefèvre S, et al. (2016) Influence of extracellular RNAs, released by rheumatoid arthritis synovial fibroblasts, on their adhesive and invasive properties. J Immunol 197: 2589-2597.

143. Cabrera-Fuentes HA, Alba-Alba C, Aragones J, Bernhagen J, Boisvert WA, et al. (2016) Meeting report from the 2nd international symposium on new frontiers in cardiovascular research. Protecting the cardiovascular system from ischemia: Between bench and bedside. Basic Res Cardiol 111: 7.

144. Cabrera-Fuentes HA, Niemann B, Grieshaber P, Wollbrueck M, Gehron J, et al. (2015) RNase1 as a potential mediator of remote ischaemic preconditioning for cardioprotection. Eur J Cardiothorac Surg 48: 732-737.

145. Cabrera-Fuentes HA, Ruiz-Meana M, Simsekyilmaz S, Kostin S, Inserte J, et al. (2014) RNase1 prevents the damaging interplay between extracellular RNA and tumour necrosis factor- $\alpha$ in cardiac ischaemia/ reperfusion injury. Thromb Haemost 112: 1110-1119.

146. Son NH, Yu S, Tuinei J, Arai K, Hamai H, et al. (2010) PPAR $\gamma$-induced cardiolipotoxicity in mice is ameliorated by PPAR $a$ deficiency despite increases in fatty acid oxidation. J Clin Invest 120: 3443-3454.

147. Morrissy S, Xu B, Aguilar D, Zhang J, Chen QM (2010) Inhibition of apoptosis by progesterone in cardiomyocytes. Aging cell 9: 799-809.

148. Shan P, Pu J, Yuan A, Shen L, Shen L, et al. (2008) RXR agonists inhibit oxidative stress-induced apoptosis in $\mathrm{H} 9 \mathrm{c} 2$ rat ventricular cells. Biochem Biophys Res Commun 375: 628-633.

149. Pu J, Yuan A, Shan P, Gao E, Wang X, et al. (2012) Cardiomyocyteexpressed farnesoid-X-receptor is a novel apoptosis mediator and contributes to myocardial ischaemia/reperfusion injury. Eur Heart J 3: 1834-1845.

150. Yao T, Ying X, Zhao Y, Yuan A, He Q, et al. (2015) Vitamin D receptor activation protects against myocardial reperfusion injury through inhibition of apoptosis and modulation of autophagy. Antioxid Redox Signal 22: 633-650.

151. He Q, Pu J, Yuan A, Yao T, Ying X, et al. (2014) Liver X receptor agonist treatment attenuates cardiac dysfunction in type 2 diabetic $\mathrm{db} / \mathrm{db}$ mice. Cardiovasc Diabetol 13: 149.

152. Singh A, Ramesh S, Cibi DM, Yun LS, Li J, et al. (2016) Hippo signaling mediators Yap and Taz are required in the epicardium for coronary vasculature development. Cell Rep 15: 1384-1393.

153. Bouchentouf M, Paradis P, Forner KA, Cuerquis J, Boivin MN, et al. (2010) Monocyte derivatives promote angiogenesis and myocyte survival in a model of myocardial infarction. Cell Transplant 19: 369-386.

154. Silva SA, Sousa AL, Haddad AF, Azevedo JC, Soares VE, et al. (2009) Autologous bone-marrow mononuclear cell transplantation after acute myocardial infarction: Comparison of two delivery techniques. Cell Transplant 18: 343-352.

155. Plewka M, Krzemińska-Pakuła M, Lipiec P, Peruga JZ, Jeżewski T, et al. (2009) Effect of intracoronary injection of mononuclear bone marrow stem cells on left ventricular function in patients with acute myocardial infarction. Am J Cardiol 104: 1336-1342.

156. Jiang M, Mao J, He B (2012) The effect of bone marrow-derived cells on diastolic function and exercise capacity in patients after acute myocardial infarction. Stem Cell Res 9: 49-57.

157. Mehta A, Sequiera GL, Ramachandra CJ, Sudibyo Y, Chung Y, et al. (2014) Re-trafficking of hERG reverses long QT syndrome 2 phenotype in human iPS-derived cardiomyocytes. Cardiovasc Res 102: 497-506.

158. Lu J, Wei H, Wu J, Jamil MF, Tan ML, et al. (2014) Evaluation of the cardiotoxicity of mitragynine and its analogues using human induced pluripotent stem cell-derived cardiomyocytes. PLoS One 9: e115648. 